\title{
Corpus Callosum and Ventricle: MRI Determination of Dementia in Turkish Population and Healthy Geriatric Subjects
}

\author{
Cuerpo Calloso y Ventrículo: Determinación de Demencia con RM \\ en una Población Turca y Sujetos Geriátricos Saludables
}

\author{
Sema Polat ${ }^{1}$; Ahmet Hilmi Yücel ${ }^{1}$ \& Mahmut Öksüzler $^{2}$
}

POLAT, S.; YÜCEL, A. H. \& ÖKSÜZLER, M. Corpus callosum and ventricle: MRI determination of dementia in Turkish population and healthy geriatric subjects. Int. J. Morphol., 35(4):1429-1436, 2017.

SUMMARY: The aim of this study was to identify the values of corpus callosum sections and ventricles in Dementia and healthy geriatric subjects using magnetic resonance imaging (MRI) and to establish both gender differences and differences between groups. The MRI results of 163 geriatric subjects ( 81 healthy individuals; 82 Dementia subjects) aged 60-89 years were studied. The midsagittal and axial images were used for measurements of the corpus callosum and lateral ventricle, respectively on MRI. The mean values of the widths of genu, body, splenium, height of the corpus callosum, longitudinal dimension of the corpus callosum and brain were $8.74 \pm 1.53 \mathrm{~mm}, 5.37 \pm 0.75 \mathrm{~mm}, 9.37 \pm 1.33 \mathrm{~mm}, 25.42 \pm 2.89 \mathrm{~mm}, 70.99 \pm 3.86 \mathrm{~mm}, 148.87 \pm 6.67 \mathrm{~mm}$ and $8.51 \pm 1.93 \mathrm{~mm}, 5.37 \pm 0.84$ $\mathrm{mm}, 9.74 \pm 1.17 \mathrm{~mm}$ and $25.67 \pm 2.88 \mathrm{~mm}, 72.41 \pm 4.99 \mathrm{~mm}, 153.66 \pm 8.00 \mathrm{~mm}$ in females and males of healthy geriatric age, respectively. The same measurements were found to be $6.90 \pm 1.66 \mathrm{~mm}, 4.33 \pm 0.76 \mathrm{~mm}, 7.94 \pm 1.38 \mathrm{~mm}, 24.42 \pm 3.11 \mathrm{~mm}, 69.01 \pm 4.52 \mathrm{~mm}, 149.18 \pm 7.13$ $\mathrm{mm}$ and $7.55 \pm 1.98 \mathrm{~mm}, 4.56 \pm 1.02 \mathrm{~mm}, 8.60 \pm 1.58 \mathrm{~mm}, 23.96 \pm 3.51 \mathrm{~mm}, 73.42 \pm 3.81 \mathrm{~mm}, 155.38 \pm 8.39 \mathrm{~mm}$ in females and males with Dementia, respectively. Additionally, the means of the frontal horn width and Evans index measurements were lower in healthy geriatric subjects, whereas the transverse inner diameter of the skull were higher in healthy geriatric subjects than dementia subjects in both sexes. The observations presented in this report have defined anatomic parameters of healthy and dementia geriatric subjects that need to be taken into consideration for reference data to determine sex discrepancies, and be helpful for radiologists and clinicians.

KEY WORDS: Corpus callosum and lateral ventricle; MRI; Dementia; Geriatric subjects.

\section{INTRODUCTION}

The corpus callosum (CC) is an important compact white matter band, anatomical and functional nerve fibres contacted in between two cerebral hemispheres. It consists of transversely situated hard myelinated nerve fibers and is located in middle cerebrum (Georgy et al., 1993; Bourekas et al., 2002; Malloy et al., 2007; Frederiksen, 2013). The $\mathrm{CC}$ develops during 8 and 20 weeks of gestation (Karakas, et al., 2011). This structure of CC provides that it is less vulnerable to ischemic lesions than gray matter (Bourekas et al.). The $\mathrm{CC}$ which includes more than 300 million fibers, takes on a supplemental task in transfering sensory, motor, and cognitive information between homologues regions in the hemispheres (Hofer \& Frahm, 2006; Ota et al., 2006). If disease affects the CC, there are some problems as visual, somesthetic, hearing, kinesthetic and function impairment (Laissy et al., 1993). Some methodologies divide the CC into four parts: the rostrum; the genu, the splenium and the body (Georgy et al.; Hallam et al., 2008). Furthermore, subregions of the CC (i.e., genu, rostrum, trunk, isthmus, splenium) are thought to play seperately different roles in cognition (Ota et al.). Many of the fibers provide homotopic connections between two hemispheres, but some atypical fibers link functionally with different cortical areas (Hofer $\&$ Frahm). The right and left cerebral hemispheres prefrontal cortex contacts with genu and rostrum. Additionally, the premotor and suplementary motor cortical regions, primary motor and sensory cortex of the two hemispheres relate with the CC body. Parietal, temporal and occipital fibers of hemispheres cross the CC via splenium (Mohammadi et al., 2011). The variations in morphology of $\mathrm{CC}$ are seen in Alzheimer disease (AD), depression, schizophrenia, dyslexia, autism (Karakas et al.; Mohammadi et al.). It is

${ }^{1}$ Cukurova University, Faculty of Medicine, Department of Anatomy. Balcalı-Sarıçam/Adana, Turkey.

${ }^{2}$ Adana Medline Hospital, Department of Radiology. Adana, Turkey. 
stated that it is not a natural aging result, It refers presence of pathological neurodegeneration which leads to cognitive decline and loss of functional abilities. It deviates from what may be expected at a given age. However, normal aging is also associated with decline in cognitive function and atrophy in grey and white matter (Miller et al., 1980; Frederiksen; Frederiksen \& Waldemar, 2012). It was reported that the CC morphology has been studied very frequently with magnetic resonance imaging (MRI) and these studies have shown that both abnormalities in $\mathrm{CC}$ and cognition and behavior are correlated with each other (Miller et al.; Ota et al.). Ventricular dimension is one of the significant measurements for evaluation of neurological diseases and ventricular growth signifies deviation of brain parenchymal structure (Karakas, et al.).

The purpose of this study was to document the normal values of corpus callosum sub-regions and lateral ventricles using MRI in healthy and Alzheimer disease geriatric females and males in our population and to identify the sex differences.

\section{MATERIAL AND METHOD}

This study was carried out from the 163 geriatric subjects ( 81 healthy individuals, 45 females and 36 males; 82 Dementia subjects, 38 females and 44 males) aged 60-89 years over a period of 2 years between January 2015 and January 2017.

All the test procedures were approved by ethics committee. Cranial MRI findings were evaluated by a radiologist and anatomist. The healthy geriatric subjects were selected by criteria of optimal health. Moreover, inclusion criteria for healthy geriatric subjects were no history of oncologic illness, no hemiplegia, no intracranial lesions, no Parkinson disease, psychiatric or medical illness. The inclusion criteria for Dementia subjects were diagnosed with dementia. MRI was performed using a 1.5 T MRI system (Siemens; Essenza, Erlangen, Germany). Brain MRI protocol including axial T2-weighted turbo spin echo (TR:3600, TE:87 ms; slice thickness $5 \mathrm{~mm}$; gap $1.5 \mathrm{~mm}$ ) and sagittal T2-weighted spin echo (TR:3600, TE: 87 ms; slice thickness $5 \mathrm{~mm}$; gap $1.5 \mathrm{~mm}$ ) was used. The measurements were performed from digital MRI images on a hospital using caliper function with $\mathrm{x} 2$ magnification. Using the midsagittal T2-weighted spin echo image, the following parameters of corpus callosum (CC) sub-regions were evaluated (Karakas, et al.; Laissy et al.; Mohammadi et al.; LeMay, 1984; O'Hayon et al., 1998; Gupta et al., 2009; Mourgela et al., 2007; Gupta et al., 2008) (Fig. 1).

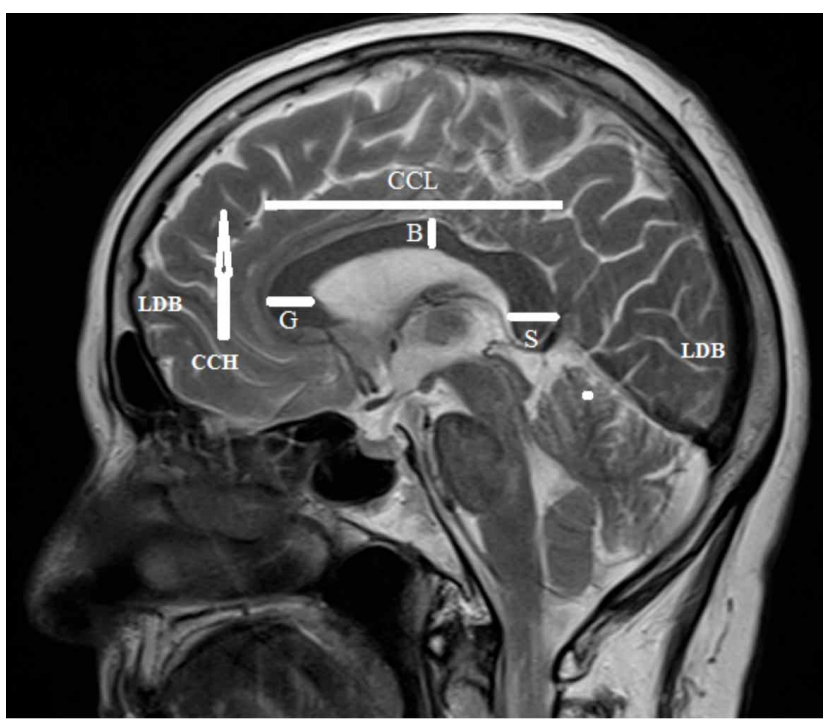

Fig. 1. Midsagittal T2-weighted Spin Echo MRI (TR:3600, TE:87 $\mathrm{ms}$ ) of measurement areas of dementia and healthy geriatric subjects. (G) The width of the genu. (B) The width of the body. (S) The width of the splenium. (CCL) The length of the corpus callosum from anterior to posterior. $(\mathrm{CCH})$ The maximum height of the corpus callosum. (LDB) The longitudinal dimension of the brain.

(G) The width of the genu

(B) The width of the body

(S) The width of the splenium

(CCL) The length of the corpus callosum from anterior to posterior

$(\mathrm{CCH})$ The corpus callosum maximum height

(LDB) The longitudinal dimension of the brain.

Two measurements were determined using T2weighted Turbo spin echo MRI. The measurements were as follows (Fig. 2).

( FH ) Frontal horn width

( TIDS) The maximum transverse inner diameter of the skull at the same level

After these measurements, Evans' ratio was calculated. This index was determined by maximum width between the frontal horns of the lateral ventricles divided by the maximum transverse inner diameter of the skull. Moreover, the ratio of the width of the body to the length of the corpus callosum (B/CCL) and the ratio of the width of the body to the height of the corpus callosum $(\mathrm{B} / \mathrm{CCH})$ were evaluated in the present study. Takeda et al., reported that evaluation of these ratios may provide an accurate interpreting of normal or pathological changes of the corpus callosum (Takeda et al., 2003).

The data were divided into two groups: dementia and healthy geriatric subjects. Estimations were expressed as 
millimeters. The SPSS 21.0 program was used for statistical analysis of the measurement results. From these measurements, means, standard deviations (SD), minimum and maximum values were calculated. $\mathrm{p}<0.001, \mathrm{p}<0.01$ and $\mathrm{p}<0.05$ were considered statistically significant.

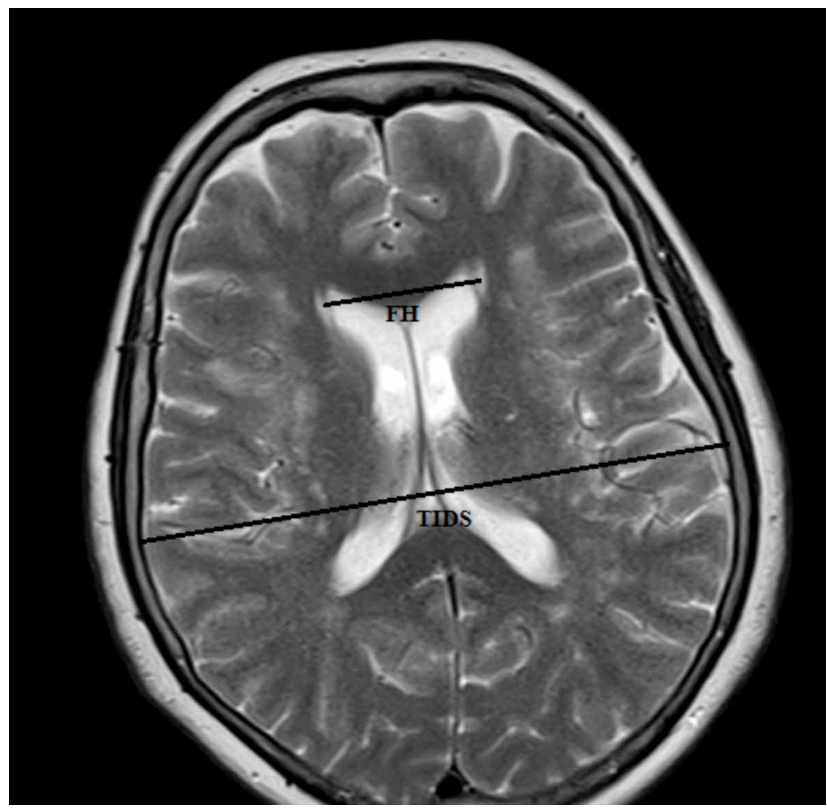

Fig. 2. Axial T2-weighted Turbo Spin Echo MRI (TR:3600, TE:87 $\mathrm{ms}$ ) of a measurement areas of dementia and healthy geriatric subjects.

\section{RESULTS}

The mean age of 81 healthy individuals ( 45 females and 36 males) was $68.82 \pm 6.27$ years and $68.83 \pm 6.38$ years in females and males, respectively. The same values of 82 subjects suffer from dementia (38 females and 44 males) were $74.92 \pm 7.19$ years and $73.09 \pm 6.85$ years in females and males, respectively.

MRI results of corpus callosum and ventricular size $(\mathrm{mm})$ in healthy geriatric and dementia subjects were shown in Table I. From the 163 MRI images, various dimensions of corpus callosum and ventricular size were measured (Figs.1 and 2). The mean scores of the widths of genu (G), body (B), splenium (S), the corpus callosum maximum height $(\mathrm{CCH})$ and the maximum transverse inner diameter of the skull (TIDS) were higher in healthy geriatric subjects than in dementia subjects, whereas the longitudinal dimension of the brain (LDB), the frontal horn width (FH) and Evans ratio (FH/TIDS) were lower in healthy geriatric subjects than in dementia subjects. Moreover, the length of the corpus callosum (CCL) were found in higher in healthy females than dementia females, while the same measurement was lower in healthy males than in dementia males. According to these results, there were statistically significantly differences in the width of the genu, body, splenium, the corpus callosum maximum height, frontal horn width and the Evans index values in between two groups. On the other hand, the longitudinal dimension of the brain, frontal horn width and the maximum transverse inner diameter of the skull findings also were statistically significant difference between sexes in two groups. Furthermore, while there were statistically difference in the only width of the splenium and the length of the corpus callosum from anterior to posterior parameters of dementia group, the mean values of these parameters were similar to healthy geriatric subjects. Additionally, the mean values of Evans' index were found as $0.28 \pm 0.03$ (females, $0,28 \pm 0,03$; males:0,28 $\pm 0,03$ ) in dementia group, whereas these values were calculated $0.27 \pm 0.02$ (females, $0,26 \pm 0,02$; males, $0,27 \pm 0,02)$ in healthy geriatric group. These values were lower in healthy geriatric subjects than in dementia subjects (Table I). On the other hand, B/CCL and B/CCH values were calculated as 0.062 (females, 0.063 and males, 0.062) and 0.075 (females, 0.078 and males, 0.073) in dementia and healthy geriatric subjects (Table I).

\section{DISCUSSION}

In this study, we measured several corpus callosum parameters, ventricular size and Evans index (calculated with formula) in both healthy geriatric and dementia subjects and compared our findings to both sexes and other populations. Moreover, there is an increase in the number of people aged 65 years or over as society is getting older. So, these type studies including geriatric population are significant in terms of showing the discrepancies in both dementia and healthy geriatric subjects at the same age with the use of MRI.

Morphological deviations in the $\mathrm{CC}$ are often found in diseases such as Alzheimer's disease, dementia, depression, autism, and schizophrenia (Weis et al., 1993; Salat et al., 1997; Yamauchi et al., 2000; Karakas, et al.; Frederiksen \& Waldemar; Frederiksen). Also, it was declared the atrophy in CC might be evaluated with Magnetic Resonance Imaging (MRI) measurements and callosal atrophy pattern may be practical which might especially show the pattern of cortical involvement related with cognitive impairment in degenerative dementia (Yamauchi et al., 2000; Hallam et al.). Atrophic changes of the CC in degenerative disease such as Alzheimer's disease (AD) are more severe than changes seen in healthy older adults. These were reduced total callosal area and stressed regional 
Table I. MRI results of corpus callosum and ventricular size $(\mathrm{mm})$ in healthy geriatric and dementia subjects.

\begin{tabular}{|c|c|c|c|c|c|}
\hline \multirow{3}{*}{$\begin{array}{l}\text { Groups } \\
\text { Measurements } \\
\text { Sexes }\end{array}$} & \multirow{2}{*}{\multicolumn{3}{|c|}{$\begin{array}{l}\text { Healthy group: } 81 \\
\text { Mean } \pm \text { standard deviation }\end{array}$}} & \multicolumn{2}{|c|}{ Dementia group:82 } \\
\hline & & & & \multicolumn{2}{|c|}{ Mean \pm st andard deviation } \\
\hline & Females $(n=45)$ & Males $(n=36)$ & & Females $(\mathrm{n}=38)$ & Males $(n=44)$ \\
\hline Age (years) & $68,82 \pm 6,27$ & $68,83 \pm 6,38$ & & $74,92 \pm 7,19$ & $73,09 \pm 6,85$ \\
\hline Genu width $(\mathrm{G})$ & $8,74 \pm 1,53$ & $8,51 \pm 1,93$ & & $6,90 \pm 1,66$ & $7,55 \pm 1,98$ \\
\hline Significance of sexes in the same group (p) & \multicolumn{3}{|c|}{$>0,05$} & \multicolumn{2}{|c|}{$>0,05$} \\
\hline Significance of two groups (p) & \multicolumn{5}{|c|}{$<0,001$} \\
\hline Body width (B) & $5,37 \pm 0,75$ & $5,37 \pm 0,84$ & & $4,33 \pm 0,76$ & $4,56 \pm 1,02$ \\
\hline Significance of sexes in the same group (p) & \multicolumn{3}{|c|}{$>0,05$} & \multicolumn{2}{|c|}{$>0,05$} \\
\hline Significance of two groups (p) & \multicolumn{5}{|c|}{$<0,001$} \\
\hline Splenium width (S) & $9,37 \pm 1,33$ & $9,74 \pm 1,17$ & & $7,94 \pm 1,38$ & $8,60 \pm 1,58$ \\
\hline Significance of sexes in the same group (p) & \multicolumn{3}{|c|}{$>0,05$} & \multicolumn{2}{|c|}{$<0,05$} \\
\hline Significance of two groups (p) & \multicolumn{5}{|c|}{$<0,001$} \\
\hline Corpus callosum length (CCL) & $70,99 \pm 3,86$ & $72,41 \pm 4,99$ & & $69,01 \pm 4,52$ & $73,42 \pm 3,81$ \\
\hline Significance of sexes in the same group (p) & \multicolumn{3}{|c|}{$>0,05$} & \multicolumn{2}{|c|}{$<0,001$} \\
\hline Significance of two groups (p) & \multicolumn{5}{|c|}{$>0,05$} \\
\hline Corpus callosum height $(\mathrm{CCH})$ & $25,42 \pm 2,89$ & $25,67 \pm 2,88$ & & $24,42 \pm 3,11$ & $23,96 \pm 3,51$ \\
\hline Significance of sexes in the same group (p) & \multicolumn{3}{|c|}{$>0,05$} & \multicolumn{2}{|c|}{$>0,05$} \\
\hline Significance of two groups (p) & \multicolumn{5}{|c|}{$<0,01$} \\
\hline Longitudinal dimension of the brain (LDB) & $148,87 \pm 6,67$ & $153,66 \pm 8,00$ & & $149,18 \pm 7,13$ & $155,38 \pm 8,39$ \\
\hline Significance of sexes in the same group (p) & \multicolumn{3}{|c|}{$<0,05$} & \multicolumn{2}{|l|}{$<0,001$} \\
\hline Significance of two groups (p) & \multicolumn{5}{|c|}{$>0.05$} \\
\hline Frontal horn width $(\mathrm{FH})$ & $33,81 \pm 3,27$ & $36,75 \pm 3,37$ & & $35,76 \pm 3,89$ & $37,62 \pm 4,27$ \\
\hline Significance of sexes in the same group (p) & \multicolumn{3}{|c|}{$<0,001$} & \multicolumn{2}{|c|}{$<0,05$} \\
\hline Significance of two groups (p) & \multicolumn{5}{|c|}{$<0,01$} \\
\hline maximum transverse inner diameter of the skull (TIDS) & $128,10 \pm 5,41$ & $133,46 \pm 6,51$ & & $127,15 \pm 5,54$ & $132,52 \pm 7,48$ \\
\hline Significance of sexes in the same group (p) & \multicolumn{3}{|c|}{$<0,001$} & \multicolumn{2}{|c|}{$<0,001$} \\
\hline Significance of two groups (p) & \multicolumn{5}{|c|}{$>0,05$} \\
\hline Evans'index & $0,26 \pm 0,02$ & $0,27 \pm 0,02$ & & $0,28 \pm 0,03$ & $0,28 \pm 0,03$ \\
\hline Significance of sexes in the same group (p) & & $<0,05$ & & & \\
\hline Significance of two groups (p) & & & $<0,01$ & & \\
\hline $\mathrm{B} / \mathrm{CCL}$ & $0,078 \pm 0,014$ & $0,073 \pm 0,012$ & & $0,063 \pm 0,012$ & $0,062 \pm 0,013$ \\
\hline Significance of sexes in the same group (p) & & $\mathrm{p}>0,05$ & & & \\
\hline Significance of two groups (p) & & & $\mathrm{p}<0,001$ & & \\
\hline $\mathrm{B} / \mathrm{CCH}$ & $0,220 \pm 0,045$ & $0,207 \pm 0,035$ & & $0,181 \pm 0,042$ & $0,193 \pm 0,048$ \\
\hline Significance of sexes in the same group (p) & & $\mathrm{p}>0,05$ & & & \\
\hline Significance of two groups $(\mathrm{p})$ & & & $\mathrm{p}<0,001$ & & \\
\hline
\end{tabular}

degeneration which was seen mostly in the anterior and posterior regions (Yamauchi et al.; Hallam et al.). It was reported that this type atrophic changes in the $\mathrm{CC}$ in normal aging appear to be analogous to patterns of cortical degeneration in AD (Hallam et al.). Additionally, in literature it was shown that the progression of clinical disease severity was correlated with the progression of atrophy of the CC (Yamauchi et al.; Hensel et al., 2002; Hensel et al., 2004; Kabay et al., 2009).

The CC which includes more than 300 million fibers, takes on a supplemental task in transfering sensory, motor, and cognitive information between homologues regions in the hemispheres (Hofer \& Frahm; Ota et al.). CC which is located in median sagittal section of the brain is an important compact white matter band (Georgy et al.; Bourekas et al.; Suganthy et al., 2003). Sometimes, the degenerative changes in $\mathrm{CC}$ can develop in time. The atrophic changes in the $\mathrm{CC}$ are seen in normal aging and dementia. Moreover, this seems to be similar to cortical degeneration in Alzheimer's disease. The connection between regional callosal atrophy and cortical degeneration was declared in other degenerative diseases such as frontotemporal dementia and in progressive supranuclear palsy (Hallam et al.). Dementia is a chronic syndrome, characterized by a progressive, relapse in intellect condition such as memory, learning, orientation, language and judgement because of disease of the brain. It mainly affects older people (age of 
65 years). It is one of the major causes of disability late in life. This syndrome is related to diseases in the brain (Prabakar \& Porkumaran, 2012). One of the most seen types of dementia is the senile dementia of the Alzheimer type. This type is observed in approximately $50 \%$ of all patients with dementia. The other reported dementia cases are multiinfarct dementia (15-20\%) and mixed forms of dementia, normotensive hydrocephalus, supranuclear palsy (Loeb \& Gandolfo, 1983).

MRI is a useful and necessary reference method to evaluate the $\mathrm{CC}$ or plan surgery lack of the risk of invasive procedures or ionizing radiation and shows differences in morphology related to sex, aging and pathologic conditions (Suganthy et al.; Gupta et al.; Karakas, et al.). Studies using MRI showed some sex differences in the size of dimensions of CC (Witelson, 1989; Salat et al.; Dubb et al., 2003; Suganthy et al.; Gupta et al.; Karakas, et al.). Moreover, females have larger splenium, greater width of trunk, and larger isthmus (Suganthy et al.). But, males have larger callosal area, genu and anterior trunk area (Witelson; Suganthy et al.; Gupta et al.). On the contrary, it was reported there was no sexual difference in the measurements of CC in Japanese subjects (Salat et al.). On the other hand, Gupta et al. declared that most of the CC parameters (except CC length) were found to be similar in both sexes in both autopsy and MRI. There was found only larger CC length in males as compared to females in the MRI group. This was explained in that it was possibly related to larger brain size in males (Suganthy et al., 2003; Gupta et al., 2008). However, it was declared that the differences in the $\mathrm{CC}$ were more associated with age than sex (Suganthy et al.). In MRI scans, It was found that width of rostrum and splenium were greater in older females (Gupta et al.). In Greek population, there was a statistically significant reduction in the longitudinal dimensions of the CC after age 45. But, there was no significant difference between 45-65 and 66-80 years (Mourgela et al.). Additionally, Suganthy reported that the $\mathrm{CC}$ was reduced with age and there were decreases in length and $\mathrm{CC}$ area. This arises from atrophy of cortical neurons, loss of white matter with aging (Suganthy et al.). It was analogous with various literature findings that proposed the splenium size difference between sexes (Holloway \& de Lacoste, 1986; Yoshi et al., 1986; Piven et al., 1997; Salat et al.; Dubb et al.; Junle et al., 2008; Karakas et al.). However, it was generally reported that males have larger bodies than females (Sullivan et al., 2001). We found the same results in dementia group but in healthy geriatric subjects, the results were similar with two sexes.

The mean values of width of genu, body and splenium were $9.4 \mathrm{~mm}, 5.8 \mathrm{~mm}$ and $10.6 \mathrm{~mm}$ in females and $9.8 \mathrm{~mm}, 6.2 \mathrm{~mm}$ and $11 \mathrm{~mm}$ in males aged from 12 to 74 years in France (Laissy et al.), whereas same values were $10.0 \mathrm{~mm}, 5.58 \mathrm{~mm}$ and $9.94 \mathrm{~mm}$ in females and $9.79 \mathrm{~mm}, 5.54 \mathrm{~mm}$ and $9.97 \mathrm{~mm}$ in males in Japanese population (Takeda et al.). However, corresponding values of two studies performed in healthy Turkish subjects were $13.28 \mathrm{~mm}, 7.64 \mathrm{~mm}$ and $12.52 \mathrm{~mm}$ in females and 13.23 $\mathrm{mm}, 6.89 \mathrm{~mm}$ and $11.90 \mathrm{~mm}$ in males respectively and $11.2 \mathrm{~mm}, 5.9 \mathrm{~mm}$ and $12.2 \mathrm{~mm}$ in healthy subjects aged between 20 and 83 years (Kabay et al.; Karakas, et al.). When we analyzed our data including witdh of genu, body and splenium were found to be $8.74 \mathrm{~mm}, 5.37 \mathrm{~mm}$ and $9.73 \mathrm{~mm}$ in females and as $8.51 \mathrm{~mm}, 5.37 \mathrm{~mm}$, and 9.74 $\mathrm{mm}$ in males, respectively. We found some differences in the average values of width of genu, body and splenium of above studies with our healthy geriatric population: The French population, Japanese population and Turkish population having greater values (Laissy et al.; Takeda et al.; Kabay et al.; Karakas et al.). On the other hand, the width of genu, body and splenium values were $7.4 \mathrm{~mm}$, $4.8 \mathrm{~mm}$ and $8.7 \mathrm{~mm}$ in France population suffer from brain atrophy (Laissy et al.), whereas these dimensions were 7,9 mm, $3.9 \mathrm{~mm}$ and $9.2 \mathrm{~mm}$ in Alzheimer patients of Turkish population (Kabay et al.). When we analyzed our findings in subjects suffer from dementia, same values were $6.90 \mathrm{~mm}, 4.33 \mathrm{~mm}$ and $7.94 \mathrm{~mm}$ in females and $7.55 \mathrm{~mm}, 4.56 \mathrm{~mm}$ and $8.60 \mathrm{~mm}$ in males respectively. Our results are different from those of these investigations when comparing the width of genu, body and splenium results: French subjects with brain atrophy having greater values than ours (except the width of genu) and Turkey population with Alzheimer having greater values than ours (except the width of body). Also, Gupta et al., reported that there was a significant difference in thickness of rostrum, genu and maximum width of $\mathrm{CC}$ in adult and senile age $(>60)$ of females and It was found that thickness of different parts of $\mathrm{CC}$ decreased with age after 60 years (17). When we investigated our data in terms of sex discrepancies females' genu, body and splenium values were found lower than males in dementia subjects. In contrast, in healthy geriatric subjects, the mean value of width of genu were found higher in females than males, whereas the mean value of splenium and body of females were similar to males.

Maximum length of $\mathrm{CC}$ was measured from anterior to posterior of CC on midsagittal section (Yamauchi et al.; Karakas et al.). The mean values of maxium length of CC were found as $75.70 \mathrm{~mm}$ and $71.00 \mathrm{~mm}$ in males and females Indian subjects, respectively (Gupta et al.). Same measurements were reported to be $71.0 \mathrm{~mm}$ and 70.3 in Iranian males and females, whereas these dimensions were found to be $70.2 \mathrm{~mm}$ and $68.4 \mathrm{~mm}$ in Greece males and 
females, respectively (Mourgela et al.; Mohammadi et al.). Moreover, these were declared as $69.7 \mathrm{~mm}$ and 69.4 in males and females in Japanese population (Takeda et al.). The same values were $73.05 \mathrm{~mm}$ and $71.27 \mathrm{~mm}$ in males and females in Turkey, respectively (Karakas, et al.). The corresponding values were declared as $74.9 \mathrm{~mm}$ in Portuguese population (Gonçalves-Ferreira et al., 2001). In our study, same meaurements were $73.42 \mathrm{~mm}-69.01 \mathrm{~mm}$ in males and females of dementia and $72.41 \mathrm{~mm}-70.99 \mathrm{~mm}$ in males and females of healthy geriatric, respectively.

Due to these data in males we found some differences in the mean values of maximum corpus callosum height of Indians, Iranians, Greece population, Japanese population, Portuguese population and Turkish adult population with our healthy geriatric male population. The Iranian and Japanese having lower, and Indian, Greece, Portuguese and Turkey adult females having greater values than ours. Similarly, when we analyzed our data in healthy geriatric female population we observed that there are differences in Iranian, Greek, Japanese, Turkish adult females, Portuguese population and our population data. But, our results are similar to those in Indian females. Moreover, when comparing the literature findings with this paper of dementia male population scores of Turkish adults and Greek population were similar to our this data. The maxium length of CC our female dementia population were found lower than above literature except the Greek population. The maximum height of $\mathrm{CC}$ were measured from two points: Between the inferior points of the rostrum and splenium to the top point of CC. Distance between these lines were taken as a reference (Takeda et al.; Karakas, et $a l$.). Moreover, mean values of maximum height of $\mathrm{CC}$ were reported between $21.8 \mathrm{~mm}$ and $25.9 \mathrm{~mm}$ (Gonçalves-Ferreira et al.; Takeda et al.; Gupta et al.; Karakas, et al.). In this study, this value was $25.67 \mathrm{~mm}-24,42 \mathrm{~mm}$ in males and females of healthy geriatric and $23.96 \mathrm{~mm}-24.42 \mathrm{~mm}$ in females of dementia subjects, respectively.

The mean values of brain length were measured as $148.87 \mathrm{~mm}$ and $153.66 \mathrm{~mm}$ in healthy geriatric females and males, respectively whereas the corresponding values were $149.18 \mathrm{~mm}$ and $155.38 \mathrm{~mm}$ in Dementia geriatric subjects. The averages of the longitudinal dimensions of brain were reported as $158.3 \mathrm{~mm}$ and $164.6 \mathrm{~mm}$ in Iranian females and males, respectively (Mohammadi et al.). The same measurements were declared as $154.4 \mathrm{~mm}$ and $151.4 \mathrm{~mm}$ in Greek males and females, respectively (Mourgela et al.). The corresponding values were found as $152.53 \mathrm{~mm}$ and 150.12 $\mathrm{mm}$ in males and females in Turkish adults. These measurents showed discrepancy from our results. However, the longitudinal dimension of the brain was higher in dementia subjects than in healthy geriatric subjects in this paper.
Ventriculomegaly or ventricular enlargement is prevalent in most neurodegenerative disorders like Alzheimer, mild cognitive impairment, schizophrenic patients and results from passive enlargement of the lateral, third and fourth ventricles following brain parenchymal narrowing. Ventricular enlargement is strongly correlated with decreases in cognitive performance (Karakas, et al.; Apostolova et al., 2012). Also, ventricular changes in time are associated with aging both in cognitively normal and diseased populations (Apostolova et al.). Lateral ventricular enlargement is evaluated with Evans index. If this index is 0.3 or greater, it shows narrowing of cerebro spinal fluid space at high midline areas (Hiraoka et al., 2008). We determined this index was maximum width between the frontal horns of the lateral ventricles divided by the maximum transverse inner diameter of the skull (LeMay; O'Hayon et al.; Hiraoka et al.; Karakas, et al.). In normal subjects over the age of 60, Evans ratio is usually equal to or less than 0.29 (LeMay; O'Hayon et al.). The Evans ratio was calculated as 27.1 and 26.2 in male and females in Japanese population. This index was found as 0.25 both in Turkish adult females and males aged between 20-50 years (Karakas, et al.). The average values of Evans ratio were higher in dementia subjects than in healthy geriatric subjects. This result is in concordance with the literature findings (LeMay; O'Hayon et al.).

The ratio of the width of the body to the length of the corpus callosum $(\mathrm{B} / \mathrm{L})$ and the ratio of the width of the body to the height of the corpus callosum $(\mathrm{B} / \mathrm{H})$ were evaluated in the present study. Takeda et al., reported that evaluation of these ratios may provide an accurate interpreting of normal or pathological changes of the corpus callosum. B/L measurement was found as 0.063 and 0.062 in females and males in dementia subjects, respectively. The corresponding values were calculated as 0.078 and 0.073 in females and males in healthy geriatric subjects, respectively. Additionally, the ratio of the width of the body to the height of the corpus callosum $(\mathrm{B} / \mathrm{H})$ value of dementia subjects were 0.181 and 0.193 in females and males, and 0.220 and 0.207 in females and males healthy geriatric subjects, respectively. In a Japanese population $\mathrm{B} / \mathrm{L}$ values 0.081 and 0.080 in females and males, respectively, whereas $\mathrm{B} / \mathrm{H}$ values were 0.219 and 0.217 in females and males, respectively (Takeda et al.). According to these data, we found differences in two ratio measurement of Japanese population with our results: They have higher values than us. Also, in this paper two index measurements were lower in dementia subjects than in healthy geriatric subjects. We think that these discrepancies may originate from race, age and sex, diseases such as dementia, Alzheimer. 
As a conclusion, the observations presented in this study have defined anatomic parameters that need to be taken into consideration to evaluate $\mathrm{CC}$ atrophy problems and guidelines for determine the reference values in terms of geriatric population. Also, this paper can provide crucial information and may be essential for safe and accurate diagnosis of many neurological disorders such as dementia, to evaluate both normal and pathological changes for surgeon, radiologist or neuroscientist about assessment of pathological changes in the $\mathrm{CC}$ and ventriculer region using with MRI. Moreover, due to aging society these kinds of studies including geriatric subjects are getting more and more important each day. The obtained data can be used as the reference values in evaluating the brain region. Furthermore, we believe that $\mathrm{CC}$ dimensions morphology and the changes related age, sex and disease will be helpful in generating reference data for healthy and dementia geriatric subjects.

POLAT, S.; YÜCEL, A. H. \& ÖKSÜZLER, M. Cuerpo calloso y ventrículo: Determinación de demencia con RM en una población turca y sujetos geriátricos saludables. Int. J. Morphol., 35(4): 1429-1436, 2017.

RESUMEN: El objetivo del estudio fue identificar los valores de las secciones del cuerpo calloso y los ventrículos en una población turca de sujetos geriátricos sanos y con demencia, mediante resonancia magnética (RM) y establecer diferencias tanto de sexo como diferencias entre los grupos. Se estudiaron los resultados de 163 sujetos geriátricos (81 sujetos sanos, 82 sujetos con demencia) de 60-89 años. Las imágenes sagitales y axiales se utilizaron para las realizar las mediciones del cuerpo calloso y del ventrículo lateral en RM, respectivamente. Los valores medios de los anchos de rodilla, cuerpo, rodete, altura del cuerpo calloso, dimensión longitudinal del cuerpo calloso y del cerebro fueron de $8,74 \pm 1,53 \mathrm{~mm}, 5,37 \pm 0,75 \mathrm{~mm}, 9,37 \pm 1,33 \mathrm{~mm}, 25,42 \pm 2,89$ $\mathrm{mm}, 70,99 \pm 3,86 \mathrm{~mm}, 148,87 \pm 6,67 \mathrm{~mm}$ y $8,51 \pm 1,93 \mathrm{~mm}, 5,37$ $\pm 0,84 \mathrm{~mm}, 9,74 \pm 1,17 \mathrm{~mm}$ y $25,67 \pm 2,88 \mathrm{~mm}, 72,41 \pm 4,99 \mathrm{~mm}$, $153,66 \pm 8,00 \mathrm{~mm}$ en mujeres y hombres sanos, respectivamente. Las mismas medidas fueron de 6,90 $\pm 1,66 \mathrm{~mm}, 4,33 \pm 0,76 \mathrm{~mm}$, $7,94 \pm 1,38 \mathrm{~mm}, 24,42 \pm 3,11 \mathrm{~mm}, 69,01 \pm 4,52 \mathrm{~mm}, 149,18 \pm$ $7,13 \mathrm{~mm}$ y $7,55 \pm 1,98 \mathrm{~mm}, 4,56 \pm 1,02 \mathrm{~mm}, 8,60 \pm 1,58 \mathrm{~mm}$, $23,96 \pm 3,51 \mathrm{~mm}, 73,42 \pm 3,81 \mathrm{~mm}, 155,38 \pm 8,39 \mathrm{~mm}$ en mujeres y hombres con demencia, respectivamente. Además, las medias de la anchura del asta frontal y las mediciones del índice de Evans fueron menores en sujetos geriátricos saludables, mientras que el diámetro interno transversal del cráneo fue mayor en sujetos geriátricos sanos que en los sujetos con demencia en ambos sexos. Las observaciones presentadas en este informe han definido los parámetros anatómicos de los sujetos sanos y con demencia que deben tenerse en cuenta para identificar los datos de referencia para determinar las discrepancias de sexo y que puedan ser útiles para los radiólogos y los médicos.

PALABRAS CLAVE: Cuerpo calloso; Ventrículo lateral; Resonancia magnética; Demencia; Sujetos geriátricos.

\section{REFERENCES}

Apostolova, L. G.; Green, A. E.; Babakchanian, S.; Hwang, K. S.; Chou, Y. Y.; Toga, A. W. \& Thompson, P. M. Hippocampal atrophy and ventricular enlargement in normal aging, mild cognitive impairment (MCI), and Alzheimer Disease. Alzheimer Dis. Assoc. Disord., 26(1):1727, 2012.

Bourekas, E. C; Varakis, K.; Bruns, D.; Christoforidis, G. A.; Baujan, M.; Slone, H. W. \& Kehagias, D. Lesions of the corpus callosum: MR imaging and differential considerations in adults and children. A. J. $R$. Am. J. Roentgenol., 179(1):251-7, 2002.

Dubb, A.; Gur, R.; Avants, B. \& Gee, J. Characterization of sexual dimorphism in the human corpus callosum. Neuroimage, 20(1):512-9, 2003.

Frederiksen, K. S; Waldemar, G. Corpus callosum in aging and neurodegenerative diseases. Neurodegener. Dis. Manag., 2(5):493-502, 2012.

Frederiksen, K. S. Corpus callosum in aging and dementia. Dan. Med. J., 60(10):B4721, 2013.

Georgy, B. A.; Hesselink, J. R. \& Jernigan, T. L. MR imaging of the corpus callosum. A. J. R. Am. J. Roentgenol., 160(5):949-55, 1993.

Gonçalves-Ferreira, A. J.; Herculano-Carvalho, M.; Melancia, J. P.; Farias, J. P. \& Gomes, L. Corpus callosum: microsurgical anatomy and MRI. Surg. Radiol. Anat., 23(6):409-14, 2001.

Gupta, E.; Lalwani, R.; Babu, C. \& Aneja, S. Age related changes of corpus callosum by MRI in females. Internet J. Neurol., 13(1):1-5, 2009.

Gupta, T.; Singh, B.; Kapoor, K.; Gupta, M. \& Kochhar, S. Age and sex related variations in corpus callosal morphology. Nepal Med. Coll. J., 10(4):215-21, 2008.

Hallam, B. J.; Brown, W. S.; Ross, C.; Buckwalter, J. G.; Bigler, E. D.; Tschanz, J. T.; Norton, M. C.; Welsh-Bohmer, K. A. \& Breitner, J. C. Regional atrophy of the corpus callosum in dementia. J. Int. Neuropsychol. Soc., 14(3):414-23, 2008.

Hensel, A.; Ibach, B.; Muller, U.; Kruggel, F.; Kiefer, M. \& Gertz, H. J. Does the pattern of atrophy of the Corpus callosum differ between patients with frontotemporal dementia and patients with Alzheimer's disease? Dement. Geriatr. Cogn. Disord., 18(1):44-9, 2004.

Hensel, A.; Wolf, H.; Kruggel, F.; Riedel-Heller, S. G.; Nikolaus, C.; Arendt, T. \& Gertz, H. J. Morphometry of the corpus callosum in patients with questionable and mild dementia. J. Neurol. Neurosurg. Psychiatry, 73(1):59-61, 2002

Hiraoka, K.; Meguro, K. \& Mori, E. Prevelance of idiopathic normalpressure hydrocephalus in the elderly population of a Japanese rural community. Neurol. Med. Chir. (Tokyo), 48(5):197-9, 2008.

Hofer, S. \& Frahm, J. Topography of the human corpus callosum revisited-comprehensive fiber tractography using diffusion tensor magnetic resonance imaging. Neuroimage, 32(3):989-94, 2006.

Holloway, R. L. \& de Lacoste, M. C. Sexual dimorphism in the human corpus callosum: an extension and replication study. Hum. Neurobiol., 5(2):87-91, 1986

Junle, Y.; Youmin, G.; Yanjun, G.; Mingyue, M.; Qiujuan, Z. \& Min, X. A MRI quantitative study of corpus callosum in normal adults. J. Med. Coll. PLA, 23(6):346-51, 2008.

Kabay, S. C.; Gulbandilar, E.; Ozden, H.; Ozbag, D.; Guven, G.; Adapinar, B. \& Durmaz, R. Evaluation of the size and area of the corpus callosum with the Osiris method in Alzheimer's disease. Neurodegener. Dis., 6(4):148-53, 2009.

Karakas, P.; Koç, Z.; Koç, F. \& Gülhal Bozkır, M. Morphometric MRI evaluation of corpus callosum and ventricles in normal adults. Neurol. Res., 33(10):1044-9, 2011.

Laissy, J. P.; Patrux, B.; Duchateau, C.; Hannequin, D.; Hugonet, P.; AitYahia, H. \& Thiebot, J. Midsagittal MR measurements of the corpus callosum in healthy subjects and diseased patients: a prospective survey. A. J. N. R. Am. J. Neuroradiol., 14(1):145-54, 1993. 
LeMay, M. Radiologic changes of the aging brain and skull. A. J. R. Am. J. Roentgenol., 143(2):383-9, 1984.

Loeb, C. \& Gandolfo, C. Diagnostic evaluation of degenerative and vascular dementia. Stroke, 14(3):399-401, 1983.

Malloy, P.; Correia, S.; Stebbins, G. \& Laidlaw, D. H. Neuroimaging of white matter in aging and dementia. Clin. Neuropsychol., 21(1):73109, 2007.

Miller, A. K.; Alston, R. L. \& Corsellis, J. A. Variation with age in the volumes of grey and white matter in the cerebral hemispheres of man: measurements with an image analyser. Neuropathol. Appl. Neurobiol., 6(2):119-32, 1980.

Mohammadi, M. R; Zhand, P.; Mortazavi Moghadam, B. \& Golalipour, M. J. Measurement of the corpus callosum using magnetic resonance imaging in the north of Iran. Iran. J. Radiol., 8(4):218-23, 2011.

Mourgela, S; Anagnostopoulou, S.; Sakellaropoulos, A. \& Gouliamos, A. An MRI study of sex- and age-related differences in the dimensions of the corpus callosum and brain. Neuroanatomy, 6:63-5, 2007.

O'Hayon, B. B.; Drake, J. M.; Ossip, M. G.; Tuli, S. \& Clarke, M. Frontal and occipital horn ratio: A linear estimate of ventricular size for multiple imaging modalities in pediatric hydrocephalus. Pediatr. Neurosurg., 29(5):245-9, 1998.

Ota, M.; Obata, T.; Akine, Y.; Ito, H.; Ikehira, H.; Asada, T. \& Suhara, T. Age-related degeneration of corpus callosum measured with diffusion tensor imaging. Neuroimage, 31(4):1445-52, 2006.

Piven, J.; Bailey, J.; Ranson, B. J. \& Arndt, S. An MRI study of the corpus callosum in autism. Am. J. Psychiatry, 154(8):1051-6, 1997.

Prabakar, S. \& Porkumaran, K. An investigation of volumetric and corpus callosum dimension to detect brain disorders. J. Biomed. Sci. Eng., 5(7):369-77, 2012.

Salat, D.; Ward, A.; Kaye, J. A. \& Janowsky, J. S. Sex differences in the corpus callosum with aging. Neurobiol. Aging, 18(2):191-7, 1997.

Suganthy, J.; Raghuram, L.; Antonisamy, B.; Vettivel, S.; Madhavi, C. \& Koshi, R. Gender- and age-related differences in the morphology of the corpus callosum. Clin. Anat., 16(5):396-403, 2003.

Sullivan, E. V.; Rosenbloom, M. J.; Desmond, J. E. \& Pfefferbaum, A. Sex differences in corpus callosum size: relationship to age and intracranial size. Neurobiol. Aging, 22(4):603-11, 2001.

Takeda, S.; Hirashima, Y.; Ikeda, H.; Yamamoto, H.; Sugino, M. \& Endo, S. Determination of indices of the corpus callosum associated with normal aging in Japanese individuals. Neuroradiology, 45(8):513-8, 2003.

Weis, S.; Kimbacher, M.; Wenger, E. \& Neuhold, A. Morphometric analysis of the corpus callosum using MR: correlation of measurements with aging in healthy individuals. A. J. N. R. Am. J. Neuroradiol., 14(3):63745, 1993 .

Witelson, S. F. Hand and sex differences in the isthmus and genu of the human corpus callosum. A postmortem morphological study. Brain, 112(Pt. 3):799-835, 1989.

Yamauchi, H.; Fukuyama, H.; Nagahama, Y.; Katsumi, Y.; Hayashi, T.; Oyanagi, C.; Konishi, J. \& Shio, H. Comparison of the pattern of atrophy of the corpus callosum in frontotemporal dementia, progressive supranuclear palsy, and Alzheimer's disease. J. Neurol Neurosurg Psychiatry, 69:623-29, 2000.

Yoshi, F.; Barker, A.; Apicella, J.; Chang, J. S. \& Duara, R. Measurements of the corpus callosum on magnetic resonance scans: Effects of age, sex, handedness and disease (abstract). Neurology, 36(Suppl.):133, 1986.

\author{
Corresponding author: \\ Dr. Sema Polat \\ Çukurova University \\ Faculty of Medicine \\ Department of Anatomy, 01330 \\ Adana \\ TURKEY
}

E-mail: sezaoz@hotmail.com

Received:14-06-2017

Accepted:05-09-2017 